\title{
Malian \\ Antiquities \\ and \\ Contemporary \\ Desire
}

\section{PATRICK R. McNAUGHTON, Guest Editor}

\section{$\mathrm{T}$}

his special issue of African Arts presents a cross-section of considered opinions regarding the 1993 emergency import restrictions imposed by the U.S. on antiquities from Mali, which give teeth to the 1970 UNESCO Convention on the Means of Prohibiting and Preventing the Illicit Import, Export and Transfer of Ownership of Cultural Property. A variety of ancient cultural materials are involved. Best known are the clay sculptures and objects from the Inland Niger Delta area around the city of Djenné (Djenne, Jenne). But all the materials (iron, wood, cloth, etc.) from the Tellem caves of the Bandiagara cliffs are also included, for example, along with works in clay from southern Mali in a style often referred to as Bankoni.

Debates about the removal of antiquities are generally very difficult, and they invoke as many perspectives as there are special interests. There are four major concerns: the cultural patrimonies and artistic heritages of people; the desire to learn about and preserve for posterity the artistic accomplishments of all cultures; the economic disadvantages that cling to people who, through accidents of history, fall outside our world's realms of affluence; and the desire to own beautiful or valuable things. From these four concerns spring tremendous contention, and there is no denying that the stakes are high.

My role is to highlight some of the issues, and I do that from my own perspective, which is that of a scholar who has worked and lived in Mali and who believes in the importance of art as a resource people can use to think about and manage their lives. Thus I add my view to the others that fill these pages, and hope that readers will find among them much that is worth their contemplation.

The first important consideration is, Who should be considered the owners of the objects being removed from Mali? The question generates ambiguity. Local people can argue that the objects should be considered theirs. The Malian government can argue that the materials are an important heritage of the whole country, and so should be protected, just as Americans try to protect the Statue of Liberty or the imagery of Mount Rushmore, or as the Greeks try to protect the architectural remains of their past.

There is also the question of whether the antiquities should be removed from Mali. The Malian government understandably considers the removal unreasonable, at least now when so little is known about them, so few are protected in the national museum, and so very little comes to Mali by way of exchange for the objects. I think Mali is best served if the accomplishments of its artistic and cultural past are comprehended and acknowledged by the rest of the world, and also preserved in the country so that its own people can garner the rich sense of identity that colonial and postcolonial practices have done so much to decimate.

But Mali struggles with very real and debilitating economic difficulties, and right now it does not have the power to overcome them all. Thus, as in so many other parts of the world, including many parts of America, many Malians must deal with poverty that

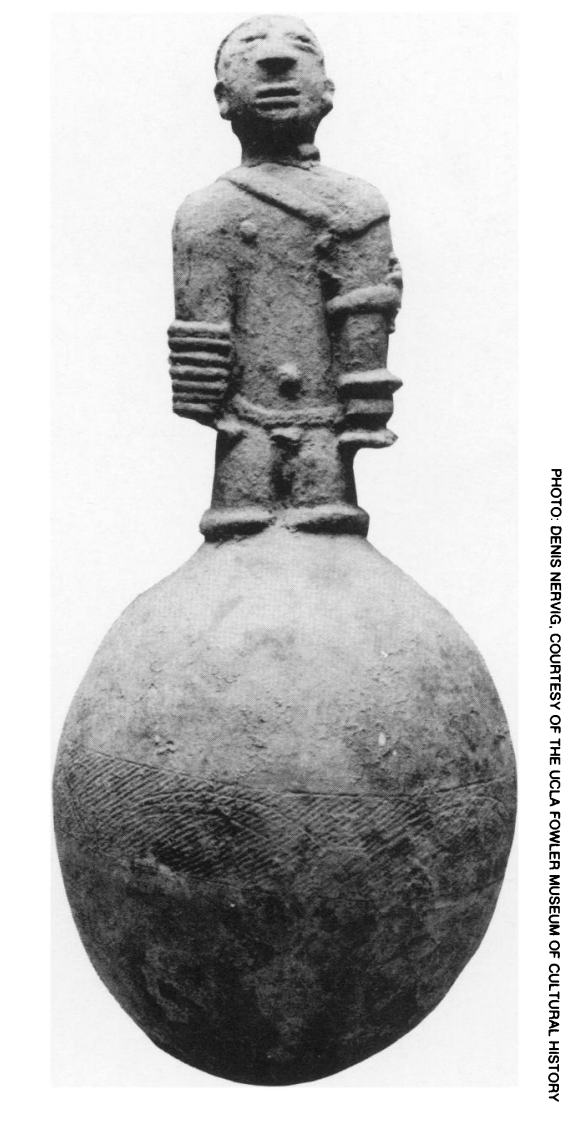

Above: Vessel with standing figure, said to be from Koulikoro village, Mali. Ca. 13th-17th century. Terracotta, $54.3 \mathrm{~cm}$ (21.4"). UCLA Fowler Museum of Cultural History, X89.375. Gift of Jerome L. Joss.

Opposite page: Seated female figure. Bankoni, Mali. Terracotta, $38.3 \mathrm{~cm}$ (15"). UCLA Fowler Museum of Cultural History, X87.1424. Gift of Jerome L. Joss. 


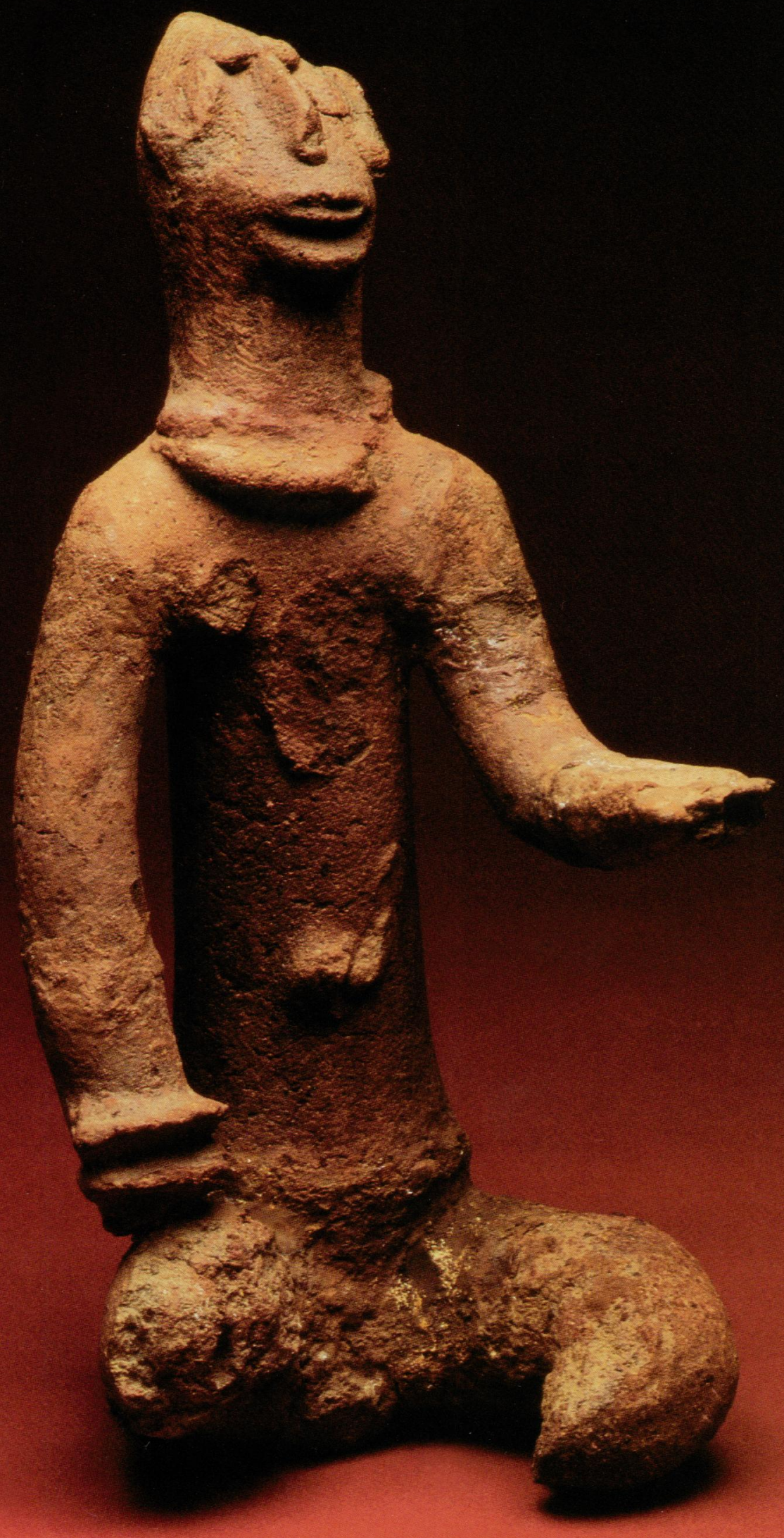



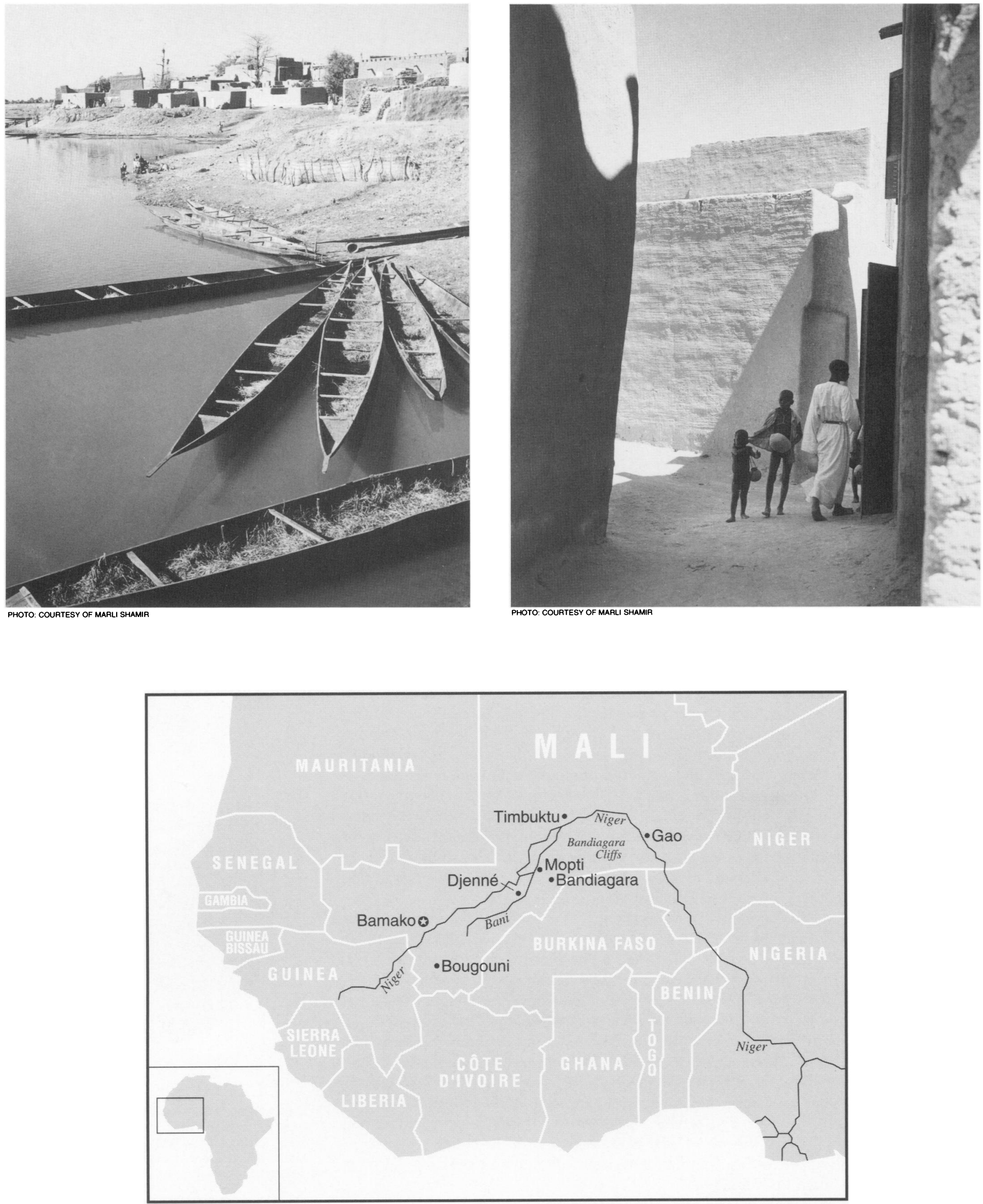


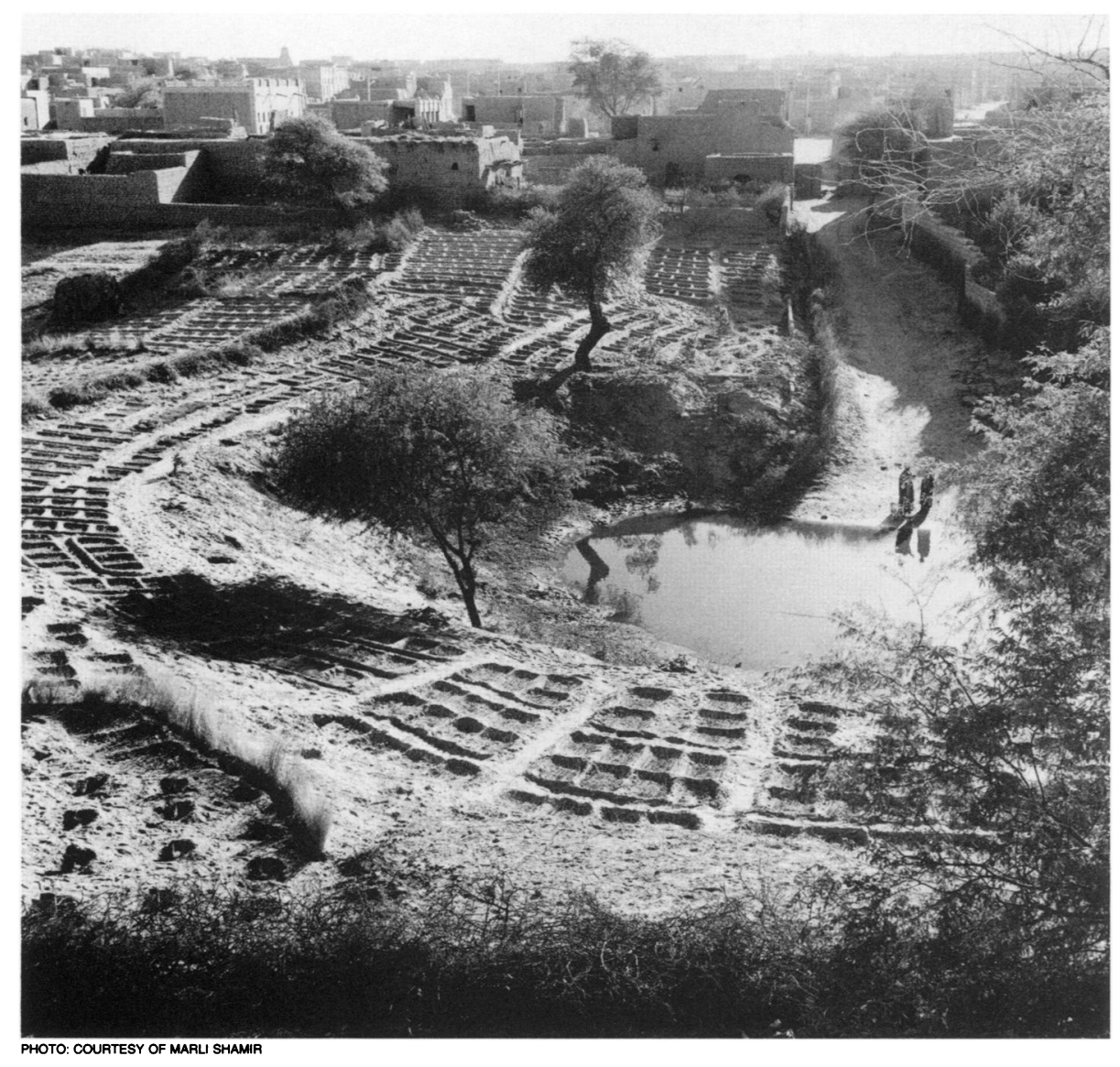

could be somewhat alleviated in exchange for these ancient cultural resources. Does this mean that Malian citizens along the Middle Niger or the Bandiagara Escarpment should be able to dig up their patrimony and sell it for profit? The Malian government is equally in need, in terms of managing and improving its infrastructure. Does that mean that the Malian government should gather up and sell these objects itself? I find it very much to Mali's credit that they have taken an honorable, far-sighted, and bold position in reference to these questions, but obviously opinions vary and many people on both sides of the Atlantic would see nothing wrong with selling the past to enhance the present.

But that leads to another, often neglected question that should be considered too. Just what do the citizens who are gathering up the objects actually get in return? It is a practical tenet of capitalism and also of the world's financial forces that money breeds more money. That often means that the people with the most generally gain the most from their financial actions, whereas the people with the least gain very little. Often those people, seeing that something small might be better than nothing at all and having little power to negotiate, exchange their material resources for what amounts to a pittance. The middle-range dealers who frequently receive the works get more, and the top-range dealers who sell to collectors end up with the most, while the collectors end up with very valuable pieces. No one offers the Malians who gather up the objects anything equivalent to the prices they will ultimately fetch. So much of the economic value of these pieces literally evaporates off the continent.

This is nothing new in the history of commoditizing art. But the disenfranchisement for Mali is compounded by another aspect of the loss. Because what is also forfeited is the distinction, prestige, and stature that human beings quite often associate with the ownership of wonderful objects, particularly when those objects are the tangible remains of a glorious past. Artworks possess a special collateral that comes from the grandeur of cultural expression, so what is also lost to Mali and Malians is a cultural resource worth at least as much as money, because cultural resources are building blocks for many of the finest ideas in a society. Artworks are among the world's most
The photographs on pages 24-27 were taken in 1971 by Marli Shamir.

Above: Dry season gardens at Timbuktu, Mali.

Opposite page, left: Djenne seen from the Bani River, Mali.

Opposite page, right: Djenne, Mali. 


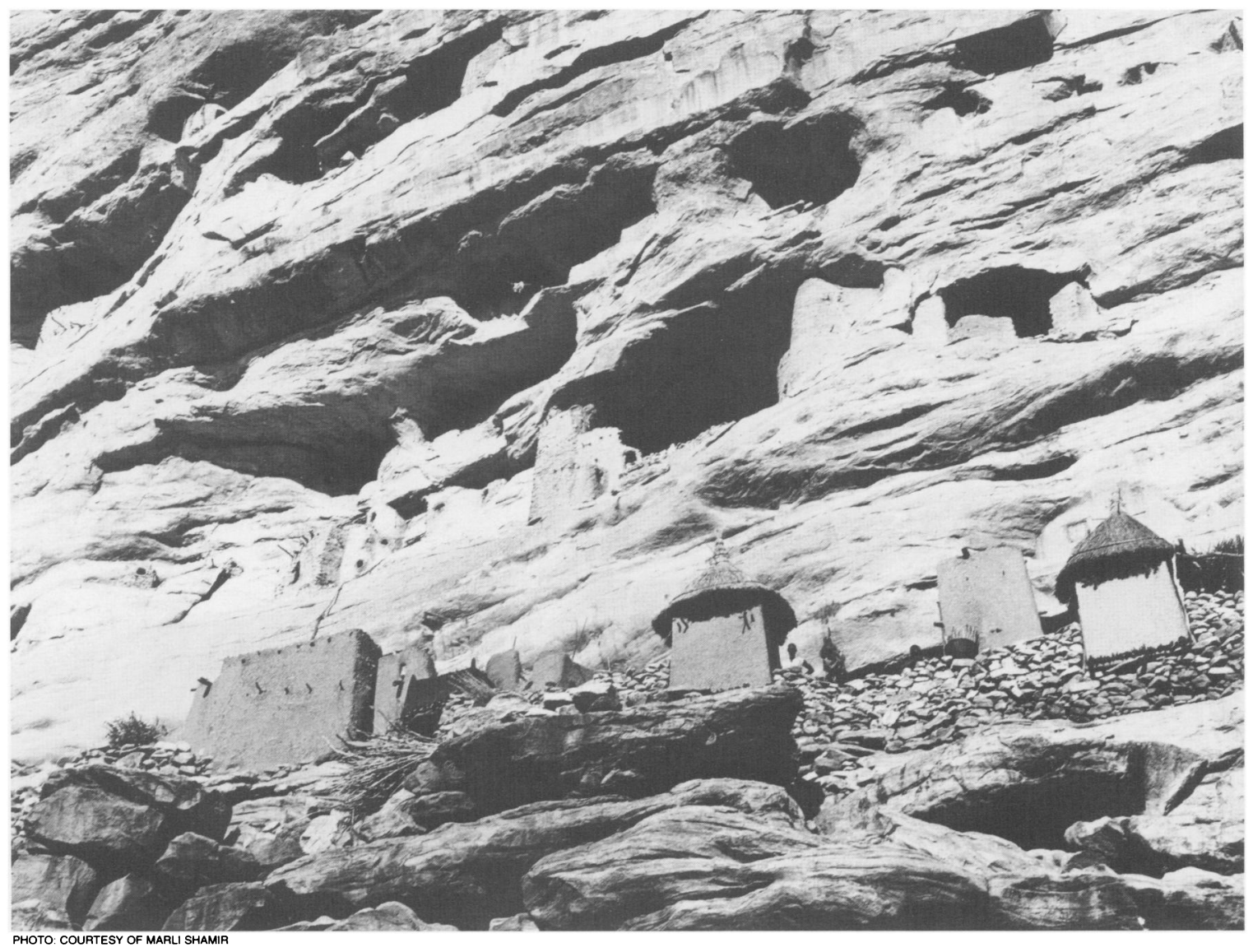

Above: Granaries at Ireli village, Bandiagara Escarpment, Dogon country, Mali.

Opposite page: Bozo fishermen at the Niger River. evocative and affecting objects. That power is nourished and amplified when it acts in networks of indigenous cause and effect. Thus, many consider it most lamentable when large numbers of a nation's antiquities are bought into foreign networks of commoditization that emphasize only material beauty, rarity, and age.

This leads to another important issue, involving the desire of many, including many scholars, to see archaeological objects removed by qualified archaeologists, so that humanity can learn what there is to know from proper excavation. Here too there are many positions to be argued, but it is worth considering the fact that all of us should know as much as we can about ancient cultural configurations and social situations, from everywhere in the world, because they can teach us things we might find useful in our attempts to improve ourselves and our world. Many would argue that thanks to the carefully researched and prolific publications of archaeologists such as the McIntoshes, our understanding of the commercial and political histories of West Africa has been vastly enhanced. It is equally easy to argue that it is in the best interests of art history that these Malian objects remain in situ until they can be extracted properly. That is the position of another accomplished archaeologist, Rogier Bedaux, whose numerous publications have also greatly enhanced our understanding of the Western Sudan's ancient history. Bedaux's "An Archaeologist's Appeal," in Illicit Traffic in Cultural Property (edited by Harrie Leyten, copublished by the Royal Tropical Institute in Amsterdam and the Musée National du Mali, 1995), deserves to be read, along with the other articles in that publication.

Of course, with each passing rainy season many of these pieces can sustain increasing damage. So perhaps it is to the benefit of everyone's knowledge to get them out of the ground and into places of safety. This is a variant of a sticky argument that has often been used to justify the removal of art from its home country. If we don't buy it, someone else will. There are not adequate museums there for the proper protection and preservation of the objects. There are not enough resources to fund research there, so shouldn't the objects be in Western collections where there might be more opportunities for scholars to examine them? 


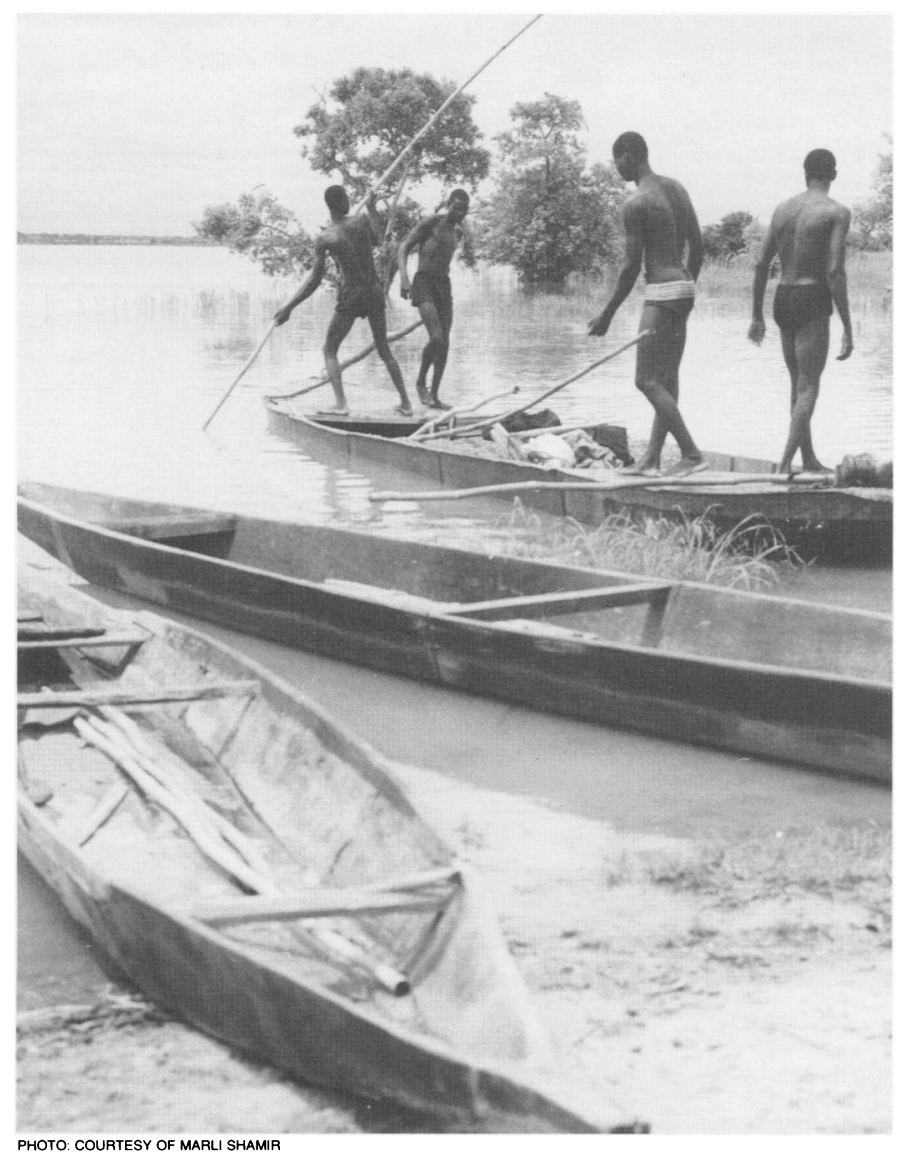

These are certainly fair questions. But they should not be asked in lieu of other questions. For example, in countries where infrastructure demands far outstrip resources, would it not be reasonable for the international community of art enthusiasts who want to own these objects to fund African museums and their staffs? Then a reasonable number of artworks could remain protected at home, while a reasonable number of artworks found new homes among the art enthusiasts of the world. Or, why don't collectors and dealers agree to offer a fair percentage of the market value of these objects to Mali, so that a more equitable distribution of benefits is established? Or, why not just agree to buy and sell the many other artworks that are on the market legitimately, and leave alone the antiquities of nations that wish to see them protected? Dealers need to earn a living. And collectors want to collect. But surely there is enough profit and delight in the pieces that can be acquired without perpetuating the old colonial formula of removing irreplaceable resources.

The articles that follow are only part of a broader literature on the issues involved in collecting. Because the economic, ethical, and emotional stakes are so high, it is reasonable to read as much as you can. In addition to Illicit Traffic in Cultural Property, another volume worth reading is The Ethics of Collecting Cultural Property: Whose Culture? Whose Property? (edited by Phyllis Mauch Messenger, published by the University of New Mexico Press, Albuquerque, 1989).

There is also a video, first seen on the program Frontline, called Plunder (produced and directed by Jim Gilmore for WGBH Educational Foundation, 1990; distributed by T.B. Video, Alexandria, Virginia). Focusing on Pre-Columbian art, it presents people from all the positions in the chain of trade, and it is probably more evocative than words alone can be. I am not suggesting that it is objective, because in our world of multiple and contentious points of view, objectivity is more an idealized than an actual possibility. But for anyone who finds this issue of African Arts interesting reading, Plunder would be worth checking out of the library. Objectivity may be hard to come by, but everyone should certainly formulate their own ethical point of view.

\section{Toward More Efficient International Collaboration}

\section{$\mathrm{T}$}

he preservation of archaeological sites and the fight against illicit trafficking constitutes, considering the vast scope of this phenomenon, a major undertaking for the people of Mali. The multiplicity and complexity of the channels involved necessitate, as never before, the establishment of an efficient international cooperative mechanism. This is why the recent decision of the United States Government to prohibit the illicit importation of archaeological objects from the Niger Valley merits the special issue that African Arts has dedicated to it.

One need only see the incomparable treasures heaped up in Western museums, the sum of the knowledge and experience they represent, and the justifiable pride of the institutions that hold them to recognize the courage and the stake involved in the American decision. Disregarding the fallacious argument that Africans are technically incapable of protecting and conserving their own archaeological objects, the decision does justice to the integrity and dignity of the cultures of the Niger Valley.

One must salute the wisdom of the American scientific community, which could have become a powerful lobby against the present agreement. This community has understood the enormous benefits that science can bring to an untouched site, as opposed to the thousands of objects scattered around the world, albeit well preserved in the best-equipped museums.

Now that this important decision has been made, I am inclined to think it is not impossible that in several years the cultural wealth of Africa, scattered across the world, as are her sons, will begin to return, enriching a free flow of exchange under the guidance of a more united and responsible international community.

Alpha Oumar Konaré President of the Republic of Mali Former President of the International Council of Museums 